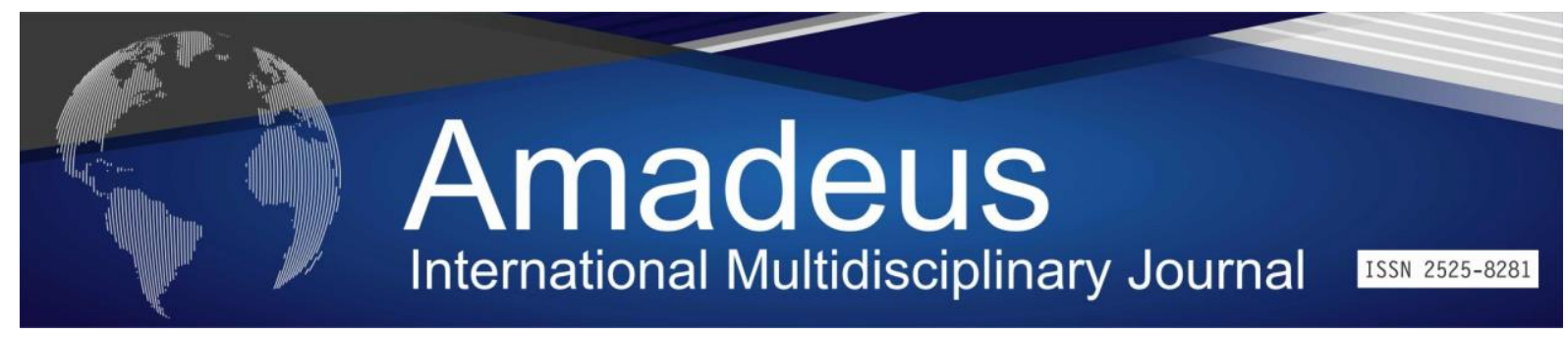

DOI: 10.14295/aimj.v5i9.147

\title{
Analysis of Male Behavior Towards Primary Health Care Services and Recommended by PNAISH in the Perception of Nurses
}

Iasmin Belém Silva Queiroz ; Allex Alves Sobral de Sousa ${ }^{2}$;

Jéssica Freire Rangel ${ }^{3}$; Luana Silva de Sousa ${ }^{4}$. José Almir de Sousa Carneiro ${ }^{5}$;

Cecília Carla Barroso Calazans $^{6}$;

Carmelita Maria Silva

Sousa ${ }^{7}$;

Francisco Rafael Soares de Sousa

Dayse Christina Rodrigues Pereira Luz ${ }^{9}$;

Willma José de Santana ${ }^{10}$

\begin{abstract}
In 2009, the Ministry of Health published the National Policy for Integral Attention to Men's Health (PNAISH). This policy calls for holistic attention and attentive to the singularities of health behaviors inherent to the male audience. However, the presence of men and the services offered are still meaningless when compared to other priority populations in Primary Care. To analyze male behavior in relation to primary health care services and recommended by PNAISH in the perception of Nurses. This is a descriptive study with a qualitative approach. Data collection took place through a semi-structured interview with Nurses of the Family Health Strategy (FHS) in the municipality of Itaitinga in the state of Ceará-Brazil. Data analysis was done based on Bardin (through coding) and the discussion in the light of the available literature. From the interviews conducted, two categories can be inferred from the light of the pertinent and updated literature: 1) Search, presence and access of men to the health service offered in Primary Care; 2) Factors involved in health care provided to the male population. These categories guided the understanding of how the reality of attention to men's health has been experienced. It is concluded that there are several obstacles that need to be overcome so that good practices in human health are feasible. For that, health practices and intersectoral and transdisciplinary discussions are needed to promote the singular approach and the individualized reception of men in health services. In order to develop together with the male population, the deconstruction of gender stereotypes that conceptualize them as invulnerable beings, provide open spaces to speak about their weaknesses and needs, having their demands welcomed and resolved, in order to approach and insert men in primary care services.
\end{abstract}

Keyword: Nursing. Public policy. Men's Health.

\footnotetext{
${ }^{1}$ Master's student in Public Policy at Universidade Athenas College. Email: iasminbelem@ hotmail.com

${ }^{2}$ Master's student in Public Policy at Universidade Athenas College. Email: allexsobralfisio@ hotmail.com

${ }^{3}$ Specialist in Health Systems Management, Auditing and Expertise at UECE. Email: jessikrangel@hotmail.com

${ }^{4}$ Master in Clinical Care in Nursing and Health from PPCCLIS / UECE. Email: lusilvasousa_@ hotmail.com

${ }^{5}$ Specialist in Intensive Care at Instituto Pro-Minas. Email:

almirrjcarneiro@gmail.com

${ }^{6}$ Residency in Transplant Assistance at UFC. Email:

ceciliacalazans@gmail.com

${ }^{7}$ Master's student in Public Policy at Universidade Athenas College. Email: carmelitasilva11@ @otmail.com

${ }^{8}$ Master's student in Public Policy at Universidade Athenas College. Email: rafa-soares@ @hotmail.com

${ }^{9}$ Post Doctoral Student in Health Sciences at the Health University Center of ABC-FMABC, Professor at the University Center of Juazeiro do Norte - UNIJUAZEIRO. Email: dayse.dcrp@ hotmail.com

${ }^{10}$ Post Doctoral Student in Health Sciences - FMABC, PhD in Biological Sciences at UFPE and Professor at Centro Universitário de Juazeiro do Norte - UNIJUAZEIRO and Faculty of Technology - FATEC - CARIRI. Email: wjsantana@hotmail.com.
} 


\title{
Análise do Comportamento Masculino frente aos Serviços de Saúde da Atenção Básica e Preconizados pela PNAISH na Percepção dos Enfermeiros
}

\begin{abstract}
Resumo: No ano de 2009, o Ministério da Saúde publicou a Política Nacional de Atenção Integral à Saúde do Homem (PNAISH). Essa política preconiza uma atenção holística e atenta as singularidades dos comportamentos de saúde inerentes ao público masculino. Contudo, a presença do homem e os serviços oferecidos ainda são inexpressivos quando comparado às demais populações prioritárias na Atenção Básica. Analisar o comportamento masculino frente aos serviços de saúde da Atenção Básica e preconizados pela PNAISH na percepção dos Enfermeiros. Trata-se de um estudo descritivo de abordagem qualitativa. A coleta de dados deu-se por meio de uma entrevista semiestruturada com Enfermeiros da Estratégia de Saúde da Família (ESF) no município de Itaitinga no Estado do Ceará- Brasil. A análise dos dados foi feita com base em Bardin (por meio da codificação) e a discussão a luz da literatura disponível. Das entrevistas realizadas pode-se inferir duas categorias analisadas a luz da literatura pertinente e atualizada: 1) Procura, presença e acesso dos homens ao serviço de saúde ofertado na Atenção Básica; 2) Fatores intervenientes na atenção de saúde prestada à população masculina. Essas categorias nortearam a compreensão de como tem sido vivenciada a realidade da atenção à saúde do homem. Conclui-se que diversos são os entraves que precisam ser superados para que sejam factíveis boas práticas na saúde do homem. Para isso, é preciso práticas de saúde e discussões intersetoriais e transdisciplinares que promovam a abordagem singular e o acolhimento individualizado do homem nos serviços de saúde. De forma a desenvolver junto à população masculina, a desconstrução dos estereótipos de gênero que os conceituam com seres invulneráveis, proporcionar espaços abertos de falas de suas fragilidades e necessidades, tendo as suas demandas acolhidas e resolvidas, com o fim de aproximar e inserir os homens nos serviços da atenção básica.
\end{abstract}

Palavras-chave: Enfermagem. Política públicas. Saúde do homem.

\section{Introdução}

A busca pelos serviços de saúde pela população masculina é menos frequente se comparada com a população feminina. Esta realidade se torna mais enfática devido a um conjunto de fatores históricos, comportamentais, sociais, culturais e pessoais que agravam este distanciamento. Tais situações reduzem a busca por ações e serviços de promoção de saúde, prevenção de doenças e melhorias na qualidade de vida, o que eleva ao aumento nas taxas de morbimortalidade e dificultam o atendimento integral e humanizado à saúde do homem (Carneiro et al, 2016). 
Diante deste cenário, observa-se a necessidade de investimento teórico-político da saúde coletiva, de forma a desenvolver ações na Atenção Básica de Saúde que venham a contribuir com a adesão aos serviços de saúde por parte da população masculina. Com o intuito de defender diferentes perspectivas e interesses, desnaturalizando condutas e práticas sociais, que envolvam a saúde pública e sejam formuladas e implementadas com foco na saúde do homem (Dantas e Couto, 2018).

Nesse sentido, o Ministério da Saúde (MS), criou em 2008, a Política Nacional de Atenção Integral à Saúde do Homem (PNAISH) com o intuito de estimular e melhorar as condições de saúde do homem brasileiro. A PNAISH propõe que o homem, em sua integralidade, tenha acesso as linhas de cuidados e as organizações de saúde, focando principalmente na faixa etária de 25 a 59 anos, zona de maior relevância dentro do cenário nacional (Brasil, 2008).

$\mathrm{O}$ atendimento integral proposto pela PNAISH propõe que a população masculina inicie seu acesso ao sistema de saúde pelo atendimento primário, ajudando a reduzir agravos evitáveis, bem como evitando processos de recuperação prolongados. Assim, existe a necessidade de focar no desenvolvimento de ações que estabeleçam a abordagem do homem pela atenção básica, de forma a identificar suas necessidades e pensando em estratégias que facilitem a adesão às ações preventivas ofertadas pelo serviço (Magalhaes et al, 2018).

$\mathrm{O}$ enfermeiro se encaixa como proponente desta integralidade ao trabalhar competências e habilidades, a partir de capacitações e conhecimento científico, a fim de melhorar a abordagem a população masculina, por meio de ações que fazem parte cotidiano do homem. Quando o enfermeiro identifica o perfil do homem, ele consegue elaborar estratégias de assistência para o mesmo de forma que ele desperte o interesse em estar mais presente nos serviços de saúde (Assis et al, 2018).

Dessa forma, o estudo tem como objetivo analisar o comportamento masculino frente aos serviços de saúde da Atenção Básica e preconizados pela PNAISH na percepção dos Enfermeiros.

\section{Metodologia}

O estudo é do tipo exploratório e descritivo, apresenta uma abordagem qualitativa. As atividades da pesquisa foram desenvolvidas em Unidades Básicas de Saúde da Família de um município do interior do Ceará, Brasil. Contou-se com 16 participantes, todos 
profissionais enfermeiros. Para guardar o anonimato dos participantes empregou-se o seguinte termo: ENF. Como critérios de inclusão os sujeitos deveriam estar vinculados à estratégia saúde da família e estarem exercendo suas atividades durante a coleta de dados. Enquanto, os critérios de exclusão foram ausentar-se do local durante a realização da entrevista e negaremse por qualquer motivo participação na pesquisa.

Realizou-se a coleta dos dados nos meses de julho e agosto de 2020, utilizando a técnica de entrevista semiestruturada, tais entrevistas foram gravadas em áudio por instrumento MP4. Os dados somente foram obtidos após explanação dos objetivos da pesquisa e sobre a participação dos mesmos no estudo, além, da assinatura do Termo de Consentimento Livre e Esclarecido. Os dados coletados foram transcritos, por meio da Análise Temática de Bardin (2010), seguindo três etapas: a pré-análise (organização e sistematização de ideias para preparar o corpus de análise); a exploração do material e o tratamento dos resultados (ocorreu mediante a codificação); inferência e a interpretação dos dados que foram analisados de acordo com a PNAISH e discutidas a luz da literatura referente à temática disponível na íntegra.

O estudo respeitou os preceitos éticas e legais propostos pela a resolução 466/2012 completada pela resolução 510/2016, ambas do Conselho Nacional de Saúde (CNS) do Ministério da Saúde. A pesquisa foi aprovada pelo Comitê de Ética em Pesquisa da Faculdade do Juazeiro do Norte- FJN no mês de julho de 2020, sendo aprovado com o número de CAAE 33070620.4.0000.5624.

\section{Resultados e Discussão}

Para melhor discutir os resultados e tendo por base a análise de dados de Bardin, elaborou-se duas categorias temáticas: 1) Procura, presença e acesso dos homens ao serviço de saúde ofertado na Atenção Básica; 2) Fatores intervenientes na atenção de saúde prestada à população masculina.

Categoria 01: Procura, presença e acesso dos homens ao serviço de saúde ofertado na Atenção Básica.

Analisando as percepções dos enfermeiros acerca de como os homens procuram e acessam o serviço de saúde, as falas evidenciaram que a procura por atendimento de saúde se dá de forma diversa a depender da idade. 
Depende da faixa etária. O homem mais jovem só procura a unidade quando ele já está em processo de adoecimento agudo [...]. E os homens mais velhos já vem à unidade geralmente por um adoecimento crônico, como a diabetes (ENF 01).

Maioria das consultas da assistência dada a esse usuário é feita de forma espontânea (ENF 07).

O comportamento masculino na saúde na faixa etária mais jovem é marcado por problemas agudos, como doenças infecciosas e derivadas de acidentes, enquanto a população mais velha é mais presente e mais dependente do serviço de saúde marcado por problemas crônicos, como hipertensão e diabetes.

A procura por unidades de saúde geralmente se dar quando a doença já é manifesta, atuando o imaginário social, de forma a inibir a atuação preventiva. Enquanto, o processo de envelhecimento aproxima os homens da unidade, tendo em vista, a instalação de doenças crônicas, geradas em algumas vezes pela deficiência do fator preventivo (Albuquerque et al, 2014).

Estudo realizado no Rio de janeiro corrobora com os achados dessa pesquisa, uma vez que a observação da tendência de mortalidade por grandes grupos de causas entre homens na referida cidade está decrescendo. Revelando uma maior cronicidade das doenças. Desafio a ser enfrentado pelos serviços de saúde, que devem planejar melhor ações voltadas a esse público com necessidades específicas (Paz et al, 2014).

Quando as falas evidenciaram o Programa Nacional de Imunização (PNI) percebeu-se que os homens comparecem as salas de vacina por motivos de emprego, acidentes e no caso de idosos por campanhas esparsas.

Agora vacinação, só tá presente se a empresa pedir, ele não vai por conta própria. Eu recebo ele vindo, encaminhado pela empresa para vacinação (ENF 03).

Vacinação, só quando levam algum corte pra vacinar contra o tétano. Ou então os idosos que vem para as campanhas da vacinação da gripe... Enfim, é o nosso público menos presente na unidade (ENF 01).

$\mathrm{Na}$ vacinação a gente não vê, na população masculina só procura se acontecer algum acidente no trabalho, ele não sabe nem porque tem que tomar...tem medo de pegar alguma doença, ou alguma lesão canina ou por gato (ENF 02).

A ausência masculina também é percebida nos programas de saúde sexual e reprodutiva; pré-natal e puericultura, atribuindo-se na maioria das falas ao fator cultural de estigma de masculinidade. 
É a coisa mais difícil do mundo. Não tem uma gestante aqui que o pai venha, que acompanhe. Nenhuma. Eles não participam (ENF 01).

Embora, a literatura aponta que a PNAISH destaca o direito ao homem de participar de todo processo produtivo, desde o planejamento familiar ao pós-parto. Nesse sentido, demanda realização de ações de saúde. Contudo, os homens são relevados pelos serviços de saúde, também evidenciado na experiência de paternidade. A saúde frequentemente reforça as barreiras do gênero, desconsidera as necessidades de saúde e responsabiliza a mulher, afastando o homem desse processo (Teixeira et al, 2014).

O estigma de gênero continua a interferir também após o parto, quando os homens não são percebidos como sujeitos promotores de saúde no meio familiar e no cuidado com os filhos.

Em relação à puericultura, eu não lembro de nenhum atendimento que eu fiz que o pai esteja presente. Não sei por que tradicionalmente se atribuiu muito a figura do cuidado a criança e aos filhos a figura materna. Aí é preconceito da própria sociedade (ENF 02).

Tá muito enraizada a cultura de achar que a mulher tem que ser responsável pelos filhos, porque não trabalha e passa o dia em casa. Tem também a questão do trabalho (ENF 06).

Estudos identificam que pais que acompanham filhos em adoecimento crônico, demonstram o valor do homem ao produzir cuidado. Este lugar de cuidado necessita romper com barreiras sociais. Os profissionais e as políticas precisam conceber práticas apoiadoras desse cuidado (Santos et al., 2018).

As necessidades masculinas no período pós-nascimento, demonstram a demanda de os mesmos serem colocados como sujeitos que precisam de cuidados particulares, além da necessidade de mudança no entendimento sobre cuidados prestados com foco na reprodução, paternidade e aspectos culturais de gênero, de tal forma que essa transformação possa impactar numa maior participação e de forma equitativa dos homens nesses processos. Assim, reque-se transformações sociais, bem como, mudanças nas políticas públicas, legislação e práticas de saúde, a fim de superar o desafio e a responsabilidade de agregar essas novas possibilidades (Teixeira et al., 2014).

No campo da saúde sexual e reprodutiva, mas uma vez o foco é nas ações voltadas para as mulheres.

Acham que só a mulher tem a responsabilidade de fazer o planejamento familiar reprodutivo. $\mathrm{O}$ homem também tem as opções do preservativo, da vasectomia, mas 
simplesmente ele deixa a cargo da mulher, como se ela fosse responsável até por essa parte sexual, da sexualidade em si e eles só participassem do ato sexual, né (ENF 06).

Apenas mulheres engravidam e com isso, a maioria dos métodos contraceptivos são direcionados ao controle feminino em primeira instância. Assim o foco das ações e serviços de saúde sexual é a mulher, sendo esta responsável pelo planejamento reprodutivo. Como se observa que a cirurgia de esterilização masculina é pouco praticada e conhecida em relação à feminina. Mesmo referente à vasectomia, a presença masculina se dá não para o planejamento, mas para a realização do procedimento cirúrgico. Ainda sobre sexualidade a vasectomia é permeada pelo medo da disfunção erétil, as consultas preparatórias para a cirurgia não são ambientes de discussão sobre sexualidade e sim de meras explicações sobre a relação da cirurgia coma preservação da função erétil e penetrativa. Assim desperdiça-se um espaço propício para debates sobre saúde do homem com foco preventivo (Ribeiro et al, 2017).

Estudos ressaltam que os profissionais enfermeiros possuem a habilidade pelo contato próximo de reconhecer as inclinações dos homens a procurarem por atendimento de planejamento familiar, dentre eles a busca para a aquisição de preservativo; esses mesmos profissionais também identificaram as predições que os afastam do planejamento familiar, destacando-se a identidade estereotipada do ser masculino, e fatores de infraestrutura e organização do próprio SUS e das UBS. Necessita-se que os profissionais de posse de tais conhecimentos atuem de forma a possibilitar reais mudanças na saúde masculina (Arruda e Marcon, 2016).

Não obstante haja o investimento em campanhas de saúde desenvolvidas frente ao câncer de pênis e próstata, as estatísticas de busca por serviços ainda evidencia-se em níveis inferiores quando comparado a outras populações. Os empecilhos frequentes nesse atendimento são o pavor da impotência sexual, o receio do diagnóstico de doenças, timidez, descredito, o predomínio de mulheres no atendimento e as prerrogativas estereotipadas do ser masculino. Outras barreiras do acesso são a indisponibilidade de serviços vinculados ao SUS, a exemplo da vasectomia, relacionada aos serviços, como a adequação dos horários, infindáveis filas de espera e longitude da moradia ou emprego, que culminam por dificultar a procura por planejamento familiar. A realidade é que o homem tem a sua disposição limitadas alternativas de participação ativa na contracepção, e constantemente está fadado à primazia do apoio, impondo barreiras para que o homem experimente sua sexualidade livre de tensões (Cesarin e Siqueira, 2014). 
O público masculino apresenta baixo índice de procura por esse atendimento de saúde, e quando o fazem, buscam devido a orientação para a saúde sexual e reprodutiva; para obtenção do preservativo; por apresentarem queixas alusivas à prevenção e diagnóstico de Infecções sexualmente transmissíveis ou por demandarem de outro serviço médico para o qual não conseguiram atendimento.

Quanto ao teste rápido eles também não procuram, a não ser que a gente detecte em alguma gestação ... ou numa prevenção também, e solicite que eles vão a uma UBS. Aí eles vão, porque querem tomar medicamento, tem a questão da praticidade (ENF 02).

Nos casos de sífilis e HIV positivo na mulher, a gente também vai contatar o parceiro para ver toda a questão do tratamento... a gente sempre tá tentando engajar. Mas ainda vemos uma resistência muito grande dos homens no serviço de saúde (ENF 10).

Ressalta-se a urgência em reavaliar as políticas de saúde pública e as práticas de prestação de serviços afim de vincular e aprimorar a participação de homens na realização de testes de Infecções sexualmente transmissíveis. De modo a estimular o envolvimento consciente e pleno na realização e no tratamento de tais doenças (Knight et al.,2016).

Os depoentes avaliaram a medicalização como um fator que influencia na procura dos homens pelo serviço, pela praticidade e resolubilidade inferiu-se que o público masculino, busca a medicação para resolução dos problemas de saúde.

É muito focado mesmo na medicação, não gosta muito de atividade coletiva. (ENF 02). Muitos homens de automedicam e a gente vê que na prática, quando chegam lá, até relatam que vão na farmácia e compram remédio pra si (ENF 06).

A prevalência é de $42,8 \%$ da utilização dos serviços de saúde por homens adultos, baixa quando comparada a outros grupos. E essa utilização dos serviços de saúde pelos homens adultos parece estar relacionada à necessidade de atenção curativa e de medicação. (Arruda e Marcon, 2016).

Atravessa-se um fenômeno denominado farmaceuticalização, que pode ser definido pelo uso excessivo ou sem prescrição médica de medicamentos para melhorar o estilo de vida, o trabalho, a cognição e o desempenho sexual entre pessoas saudáveis. E segundo Esher e Coutinho (2017), esse fenômeno tem sido indicado como um entrave ao estabelecimento do uso racional de medicamentos. É essencial que as políticas e programas de saúde do homem, levem em consideração essas associações.

Categoria 02: Fatores intervenientes na atenção de saúde prestada à população masculina. 
Os profissionais identificam os fatores que interferem na procura e acesso dos homens ao serviço, mas quando questionados sobre os estímulos que eles desempenham em trazer os homens para UBS, os mesmos reconhecem que se empenham pouco nesse sentido. Por vezes, a presença masculina é encarada com estranhamento.

Não. A gente não estimula isso, a gente se acomoda. E a gente até estranha quando vê, né? A gente vai fazer uma puericultura e a gente estranha quando tá o pai e a mãe. Principalmente se chegar só o pai com a criança, a gente acha muito estranho (ENF 14).

Acaba que a gente não estimula pela própria estrutura da atenção primária, pelas cobranças que a gente tem várias coisas pra cumprir, a gente é cobrado por vários programas e aí, como o próprio programa da atenção à saúde do homem ele ainda não traz aqueles indicadores que impactam na questão da gestão, que faz tanta diferença, acaba que a própria gestão não cobra da gente ações voltadas para a saúde do homem. Uma questão de estímulo que vem lá da política, que não traz muito indicador de gestão, a gestão em si não vê muito retorno aí não cobra muito dos profissionais e esses acabam priorizando outras coisas. (ENF 02).

A ausência de estímulos ao público masculino mais uma vez é justificada pela deficiência da própria gestão, nesse momento fez-se menção a todos os âmbitos de governo: federal, estadual e municipal.

A gestão é omissa de uma forma geral e na saúde do homem também (ENF 05).

Mas eu não acho que nem o Governo Federal, nem, Estadual, nem Municipal ele tem um olhar tão atento, tão acolhedor, tão individual como ele tem pra saúde da mulher (ENF 03).

O que a gente vê na prática o Ministério sempre prioriza quem? São as crianças, o PNI, a saúde da mulher em geral, a questão da prevenção do câncer de mama, do câncer do colo uterino...isso daí são as políticas mais implementadas e também a parte do hipertenso e diabético que é implementado no geral (ENF 06).

Com vista a aprofundar essa discussão, um estudo problematizou a incorporação da dimensão das masculinidades como fomentadora de estratégias de gestão na PNAISH, e identificou que os discursos reducionistas sobre o estigma do ser homem e sua relação com saúde são desprovidos de uma reflexão que outros indicadores, como classe social e raça, produzem iniquidades em saúde, influenciando no reconhecimento como sujeito de direitos, desigualdade, discriminação, vulnerabilidades e adoecimento dos homens (Cesaro et al, 2018).

Assim por vezes, o homem não foi um ser protagonista na esfera da saúde pública. Sendo a mulher, criança e idosos as prioridades de programas e políticas públicas no Brasil (Dutra et al, 2012). Nesse sentido, Miranda et al, (2018), enfatizam que os serviços da Atenção Básica de Saúde devem organizar sua atuação de acordo com as demandas 
individuais, específicas e os problemas de maior prevalência no território adscrito, incluindo a saúde do homem.

Demonstrou-se que os profissionais reconhecem a necessidade de trabalhar com a população masculina, sendo preciso incentivo e fortalecimento para essas práticas. Para isso, é necessário discussões intersetoriais, inclusive com a gestão, para aproximação do homem ao serviço de saúde, mudança do paradigma da masculinidade e capacitação profisssional (Araújo et al, 2014).

Alguns participantes destacam que a política do homem por não estar totalmente efetivada e implementada, não gera recursos financeiros e assim não é foco primordial da atenção básica.

A gestão acaba não estando muito focada na saúde do homem, não tem estímulo, porque o que estimula a gestão é retorno financeiro, aí acaba que não tendo muito impacto financeiro, aí a gestão não bota como prioridade, até porque tem outras políticas que são mais rentáveis, trazem mais recursos e são mais priorizadas. (ENF 02).

A gestão deve ser uma apoiadora do processo de efetivação, providenciando instrumentos para a atenção integral masculina, que viabilize a inserção nos serviços de saúde pela porta de entrada da atenção básica, estimulando a prevenção e promoção de saúde e não apenas a recuperação como é frequentemente percebida na atenção especializada. Nota-se a necessidade de ampliação da atenção, cuidado singular e construção da saúde de forma coletiva, desvinculadas das barreiras da ideia de gênero. $O$ cuidado deve transpor a unidade básica deve-se usar de criatividade e usar outras formas de se fazer saúde, sendo indispensável à resolubilidade dos problemas (Araújo et al., 2014).

Porém, não só a gestão foi responsabilizada pelos enfermeiros, estes também corresponsabilizaram-se no processo de luta pelos direitos de saúde da população masculina, enfatizando a necessidade da educação permanente e capacitação para o alcance das conquistas.

E, quem é responsável pela política? Os profissionais e também os órgãos responsáveis. A partir do momento em que eles são conscientizados e informados do que é a política, eles também devem ser conscientes de que, para a política funcionar, eles também têm que participar da implementação daquela política em si. A gente trabalha muito a questão voltada ao trabalho, mas seria muito importante, além de um maior empenho do MS, também se ter uma integração do MS e do MEC, na parte de graduação. Pelo menos na minha graduação, foi muito deficiente essa parte de políticas em si. (ENF 06)

A deficiência do preparo profissional é remetida a graduação, na qual reflete-se que a política de saúde do homem é insuficientemente debatida. Faz-se necessários que os 
ambientes acadêmicos sejam parceiros e colaboradores no processo de efetivação das políticas (Queiroz et al, 2018).

Apontou-se dificuldades para a implementação, como deficiência de recursos materiais, pessoais e falta de interesse do próprio homem. Essas dificuldades necessitam ser analisadas e solucionadas, com o apoio inclusive da gestão (Carneiro et al, 2016).

Assim, outra atuação estratégica para a inserção do homem nos serviços de saúde darse pela realização de educação permanente e capacitação com profissionais de saúde frente a melhor atuarem junto à PNAISH. Para tanto, faz-se necessário que essa educação voltada à saúde do homem se inicie ainda no período de graduação desses profissionais, tendo em vista que a prática revela que há um pouco preparo para a assistência terapêutica desse público. Sendo ainda indispensável, a readequação dos serviços de saúde pelos gestores no contexto econômico, político e institucional (Albuquerque et al, 2014).

Ainda sobre o fator gênero e sua influência na saúde dos homens, os enfermeiros apontaram como empecilhos ao acesso masculino aos serviços de saúde: o medo, a vergonha e a falta de conhecimento.

\footnotetext{
Vergonha, o homem é muito tímido. No atendimento eles estão sempre de cabeça baixa. Acho que a vergonha é um fator (ENF 08).

O que impede é o conhecimento, de que eles não teriam certas doenças se eles pudessem prevenir, se não estivesse mais avançada. E como te falei, só vem quando estão sentindo alguma coisa. (ENF 12).

$\mathrm{Na}$ verdade, é que o homem tem medo do atendimento, então ele só vem realmente quando tá mal, senão não vem (ENF 13).
}

Identificou-se que os profissionais precisam romper com as barreiras do machismo e assistencialismo para que essa população possa ser sujeitos protagonistas de sua própria saúde, estimulando a promoção saúde e prevenção de agravos, gerando um serviço de saúde singular e qualificado desenvolvida aos homens idosos (Queiroz et al, 2018).

Desse modo, no que tange a promoção de saúde do homem, vê-se a necessidade de uma abordagem inclusiva do homem nos cuidados que visam à família, que mesmo embora uma construção sociocultural tenha colocado a mulher como sujeito promotor de saúde da família, na atualidade a população masculina tem se mostrado disponível e proativo para o cuidado com a família.

A PNAISH enfoca a necessidade do estímulo para o homem cuidar de si e de sua família, sendo preciso tê-lo como indivíduo receptor de orientações de saúde. Tal prática inclusiva desenvolve sentidos, significados e sentimentos que os impulsionam 
ao empoderamento enquanto sujeitos também produtores de cuidado. O que leva a romper com as barreiras de gênero.

Solução seria o fortalecimento do vínculo e desenvolvimento de estratégias inovadoras para tentar trazer esse público para cuidar da própria saúde, que teria que estar de tempos em tempos promovendo essas ações ... sempre tentar abranger esse público masculino. (ENF 15).

Destaca-se a necessidade de horários diferenciados e atividades que promovam a integração do homem com a Atenção Básica, sendo necessários recursos materiais e pessoais. Pode-se mencionar ainda o despreparo por parte das profissionais mulheres para lidar com situações que exijam exame físico no homem.

Pesquisas apontam que entre os homens encontram-se elevadas índices de prevalência de comportamentos de risco à saúde e demonstram que os aspectos sociodemográficos estão atrelados a esses comportamentos, de forma a contribuir para o aumento de ocorrência ou a proteção. Logo, tais pesquisas apresentam associações essenciais a serem consideradas no planejamento e implementação das ações em saúde do homem (Arruda e Marcon, 2018).

O que corrobora com o presente estudo, uma vez que depoentes identificaram que a depender do conhecimento, classe social e poder aquisitivo, os homens procuravam mais as unidades de saúde.

\footnotetext{
Mas há alguns casos em que acontece, inclusive é muito interessante, só que eu percebo que eles ainda participam de uma forma muito passiva, somente no papel de acompanhante, só observando e não falam nada, eles tão começando a vir em alguns casos mais nesse sentido de passividade. (ENF 15)

É rara a presença do homem, que é quando a pessoa tem algum conhecimento melhor, algum poder aquisitivo, que vem um ou dois acompanhando a esposa pra fazer alguma vacina no filho (ENF 16).
}

Apesar do progresso, o homem ainda é resistente em procurar pelo serviço de saúde, principalmente nas camadas populares mais baixas, onde os traços culturais são marcantes e o acesso às informações em saúde limitadas.

Identificou-se relação entre aspectos socioeconômicos e demográficos com índices de demanda em saúde para homens na idade adulta, o que vem a estabelecer padrões inovadores para futuras práticas de saúde individualizados para a população masculina. O estudo evidencia que é imprescindível ponderar a autopercepção masculina, bem como a morbidade, fatores relacionados e particularidades do gênero (Arruda et al, 2014).

É inegável que fatores como o baixo grau escolar, discrepância social de renda, condições insalubres de moradia, excesso de trabalho e precária mobilidade urbana estão 
relacionados aos elevados índices de segregação masculina dos serviços de saúde (Miranda et al, 2019).

Ainda segundo Gaspodini (2017), as condições financeiras e sociais apresentam-se com indicativos frequentes para a discriminação nos serviços de saúde, influenciando nos cuidados à saúde. Nessa perspectiva, deve-se considerar a associação entre renda, classe social e demais marcadores sociais de desigualdade, nas pesquisas sobre as necessidades singulares de atenção à saúde dos homens.

Uma fala destacou a necessidade de se trabalhar o público masculino desde a infância, com vista a romper os estigmas culturais.

A gente pode trabalhar nas escolas, que é a base. Você pegar já o homem na sua fase de adolescência pra você colocar a cultura de que ele tem que procurar a unidade de saúde. Porque essa faixa etária dos adultos acima dos trinta anos é meio complicado eles virem. Agora, se você começar a trabalhar na base, na saúde escolar, aí você tem pra um futuro um povo mais consciente (ENF 16).

Condutas adotadas por homens na vida adulta foram reproduzidas ao que fora vivenciado na infância. É preciso criar estratégias que viabilizem a ressignificação. A desconstrução das barreiras de sociais é necessária à construção da saúde integral do homem (Lírio et al, 2018).

Um enfermeiro reflete que a política de saúde do homem ainda precisa ser muito trabalhada e para isso todos os atores da saúde precisam estar envolvidos e dispostos ao desenvolvimento da saúde do homem.

Ainda está em passos de engatinhamento, precisa trabalhar o profissional, o próprio usuário e precisa haver projetos mais específicos para essa assistência. Precisa ter também mais informação, dar mais informação ao cidadão. A forma de abordagem é extremamente importante e a gente aguarda que daqui há alguns anos essa política seja efetiva (ENF 07).

Reflexo de que a saúde masculina precisa ser desenvolvida em meio a diálogos entre os atores: indivíduos, família, sociedade, enfermagem, saúde e autoridades públicas (Portela et al, 2016).

\section{Considerações finais}

Conclui-se que diversos são os entraves que precisam ser superados para que sejam factíveis boas práticas na saúde do homem. Para isso, é preciso práticas de saúde e discussões intersetoriais e transdisciplinares que promovam a abordagem singular e o acolhimento 
individualizado do homem nos serviços de saúde. De forma a desenvolver junto à população masculina, a desconstrução dos estereótipos de gênero que os conceituam com seres invulneráveis, proporcionar espaços abertos de falas de suas fragilidades e necessidades, tendo as suas demandas acolhidas e resolvidas, com o fim de aproximar e inserir os homens nos serviços da atenção básica.

Muito se ressaltou que a gestão municipal assume papel primordial na luta pelos direitos de saúde desse grupo, devendo apoiar e desenvolver estratégias que promovam a atenção integral ao homem. É necessário qualificações através de educação permanente, atuação junto as instituições de ensino superior, mudanças das práticas de saúde e na organização do trabalho, que valorizem os profissionais e usuários.

\section{Referências}

Albuquerque G. A. et al. (2014). Enfermeiros e saúde do homem na atenção básica. Escola Anna Nery Revista de Enfermagem, v. 18, n. 4. DOI: http://dx.doi.org/10.5935/14148145.20140086.

Araújo M. G. et al. (2014). Opinião de profissionais sobre a efetivação da Política Nacional de Atenção Integral à Saúde do Homem. Esc. Anna Nery, v. 18, n. 4, p. 682-689. DOI: http://dx.doi.org/10.5935/1414-8145.20140097.

Arruda G. O. \& Marcon S. S. (2018). Comportamentos de riscos à saúde de homens da região sul do Brasil. Texto Contexto Enferm, v. 27, n. 2. DOI: http://dx.doi.org/10.1590/0104070720180002640014.

Arruda G. O. \& Marcon S. S. (2016). Inquérito sobre a utilização dos serviços de saúde por homens adultos: prevalências e fatores associados. Rev. Latino-Am. Enfermagem, v.24, p. 1-9.

Assis N. O. et al. (2018). The role of nurses in the national policy of integral health care for men: an exploratory study. Arq. Cienc. Saúde UNIPAR, Umuarama, v. 22, n. 3, p, 151-156.

Bardin L. (2010). Análise de conteúdo. Trad. Luís Antero Reto e Augusto Pinheiro. Lisboa: Edições, v.70, p.281.

BRASIL. (2008). Ministério da Saúde. Política Nacional de Atenção Integral à Saúde do Homem: princípios e diretrizes. Brasília (DF).

Carneiro C. M. R. et al. (2016). Comprehensiveness in men's health care: a challenge in primary care. Rev. Bras. Promoç. Saúde, Fortaleza, v. 29, n. 4, p. 554-563.

Cesarin S. T. \& Siqueira H. C. H. (2014). Planejamento familiar e a saúde do homem na visão das enfermeiras. Esc Anna Nery, v. 18, n. 4, p. 662-668. 
Cesaro B.C. et al. (2018). Masculinidades inerentes à política brasileira de saúde do homem. Rev Panam de Salud Publica, v. 42, p. 119-126. DOI: http://dx.doi.org/10.26633/RPSP.2018.119.

Dantas S. M. V. \& Couto M. T. (2018). Sexualidade e reprodução na Política Nacional de Saúde do Homem: reflexões a partir da perspectiva de gênero. Revista Latino-americana, n. 30, p. 99-118.

Dutra D.G.; et al. (2012). Saúde do homem: uma visão sociocultural sobre a Política Nacional de Atenção Integral a Saúde do Homem. In: III Seminário de Pesquisas e TCC da Faculdade União de Goyazes, Trindade: FUG.

Esher A. \& Coutinho T. (2017). Uso racional de medicamentos, farmaceuticalização e usos do metilfenidato. Ciência \& Saúde Coletiva, Rio de Janeiro, v. 22, n. 8, p. 2571-2580.

Gaspodini Í B. et al. (2017). Masculinidades em diálogo: produção de sentido a partir de marcadores sociais da diferença. Mudanças Psicologia da Saúde, São Paulo, v. 25, n. 1, p. 1725 .

Knight R. et al. (2016). Integrating gender and sex to unpack trends in sexually transmitted infection surveillance data in British Columbia, Canada: na ethnoepidemiological study. BMJ Open, v. 6, p. 11-20. DOI: http://dx.doi.org/10.1136/bmjopen2016-011209.

Lírio J. G. et al. (2018). Abuso intrafamiliar na infância de homens em processo criminal por violência conjugal. Acta Paul Enferm, v. 31, n. 4, p. 423-429. http://dx.doi.org/10.1590/19820194201800059 .

Magalhaes M. C. et al. (2018). Assistance to the male population in the primary care of Maracanaú-CE: a documentary study. Rev. APS, v. 21, n. 4, p. 737-746.

Miranda S. V. C. et al. (2019). Necessidades e reivindicações de homens trabalhadores rurais frente à atenção primária à saúde. Trab. Educ. Saúde, v. 18, n. 1.

Miranda S. V. C. et al. (2018). A visão do homem trabalhador rural norte-mineiro sobre o cuidado em saúde no contexto da atenção primária à saúde. Ciência \& Saúde Coletiva, Rio de Janeiro, v. 4, n. 9.

Paz E. P. A. et al. (2014). Análise da tendência da mortalidade masculina no Rio de Janeiro: contribuição da enfermagem. Esc Anna Nery, v. 18, n. 4, p. 593-599, 2014.

Portela P. P. et al. (2016). Fatores associados ao descontrole da pressão arterial em homens. Acta Paul Enferm, v. 29, n. 3, p. 307-315.

Queiroz T. S. et al. (2018). Como homens idosos cuidam de sua própria saúde na atenção básica? Rev Bras Enferm, v. 71, n. 1, p. 599-606.

Ribeiro C. R. et al. (2017). Encontros e desencontros entre a saúde do homem, a promoção da paternidade participativa e a saúde sexual e reprodutiva na atenção básica Physis Revista de Saúde Coletiva, Rio de Janeiro, v. 27, n. 1, p. 41-60. DOI: http://dx.doi.org/10.1590/S010373312017000100003. 
Santos R. N. C. et al. (2018). Men's position in family care on situations of chronic illness. Rev Esc Enferm USP, v. 52, p. 39-48. DOI: http://dx.doi.org/10.1590/S1980220X2017046703398.

Teixeira R. C. et al. (2014). Vivências e necessidades de saúde de homens no período pósnascimento de um filho. Rev Bras Enferm, v. 67, n. 5, p. 780-787.

\section{How to cite this article (APA format):}

Queiroz, Iasmin Belém Silva; Sousa, Allex Alves Sobral de; Rangel, Jéssica Freire; Sousa, Luana Silva de; Carneiro, José Almir de Sousa; Calazans, Cecília Carla Barroso; Sousa, Carmelita Maria Silva; Sousa, Francisco Rafael Soares de; Luz, Dayse Christina Rodrigues Pereira; Santana, Willma José de (2020). Analysis of male behavior towards primary health care services and recommended by PNAISH in the perception of nurses. Am. In. Mult. J., Jul to Dec (9) 5, 278-293.

Received: 11/11/2020;

Accepted: 11/26/2020. 